\title{
PENGARUH ECONOMIC SHOCK TERHADAP PENERIMAAN PAJAK PADA KANTOR WILAYAH PAJAK DI INDONESIA
}

\author{
Eddi Wahyudi ${ }^{1}$ \\ Bunasor Sanim ${ }^{1}$ \\ Hermanto Siregar ${ }^{1}$ \\ Nunung Nuryartono ${ }^{1}$ \\ ${ }^{1}$ Sekolah Pascasarjana (S3) Institut Pertanian Bogor \\ E-mail: eddywahyudi34@yahoo.co.id
}

\begin{abstract}
The purpose of this research is to analyse how far the economic shock influence upon the tax revenue performance in the regional tax office. The research is conducted using yearly time series data within 2002 to 2007 and also applying two indicators: Income Tax and Value Added Tax. By using the panel data analysis the result upon 31 Kanwil Directorate General of Tax (DGT) whole Indonesia it is known that the fluctuation variable of Tax Early Warning System (TEWS) gives positive effect to the tax income performance at Kanwil Khusus, Kanwil WP Besar 1 and 2, Kanwil Jakarta Selatan and Kanwil Jakarta Pusat. Overall the entire research result explains that Indonesia economic condition until he year of 2007 is still in the small open economy status and identically to New Keynes theory. The conclusion is as if the research about the Indonesia business cycle previously and consistent with the initial assumption applied.
\end{abstract}

Keywords: business cycle, economic shock, tax early warning system, pendapatan pajak

\section{PENDAHULUAN}

Penerimaan pajak merupakan dampak akumulasi agregat ekonomi yang tercermin dari aktifitas bisnis, meskipun fluktuasinya tidak secara jelas tergambar. Dengan demikian kinerja penerimaan pajak sangat tergantung dari aktifitas bisnis yang ada. Fluktuasi siklus bisnis tersebut sangat tergantung pada pola keseimbangan antara permintaan dan penawaran, dimana gangguan bersifat eksternal maupun internal dapat menyebabkan terjadinya dissequilibrium yang mengakibatkan deviasi output terhadap tren yang sedang berlaku. Shock akan menyebabkan fluktuasi ekonomi yang mengakibatkan terjadinya penyimpangan output terhadap tren berupa kontraksi atau ekspansi ekonomi yang kemudian akan membentuk sebuah pola siklus naik turun disebut dengan business cycle.

Dampak dari shock akan menyebabkan terjadinya fluktuasi ekonomi yang pada akhirnya akan tertransmisi pada naik dan turunnya penerimaan pajak. Terganggunya penerimaan pajak akan mempengaruhi tiga aspek penting secara terintegrasi, yaitu: 
ekonomi, politik dan sosial. Pengabaian terhadap adanya hubungan keterkaitan antara ketiga aspek ini akan menurunkan kinerja pemerintah yang pada gilirannya akan menurunkan kepercayaan masyarakat.

Atas dasar pertimbangan tersebut maka turbulensi lingkungan harus dapat dideteksi secara dini oleh organisasi agar dampak guncangannya dapat diantisipasi secara cermat melalui serangkaian kebijakan tertentu. Deteksi dini melalui peramalan siklus perekonomian tersebut sangat penting bagi pemerintah dalam rangka perencanaan dan formulasi kebijakan. Model siklus bisnis ini diperlukan mengingat pengelolaan penerimaan negara sangat rentan akibat guncangan (shock) yang ditimbulkan oleh turbulensi lingkungan. Namun demikian melalui model tersebut belum dapat diketahui secara detail seberapa besar pengaruh perubahan fluktuasi variabel makro ekonomi terhadap penerimaan pajak di masing-masing Kantor Wilayah Pajak (Kanwil) di Indonesia, sehingga diperlukan analisis lanjutan untuk lebih mendalami seberapa besar pengaruhnya. Dengan demikian penelitian ini perlu dilakukan agar dampak shock terhadap fluktuasi siklus bisnis dan kinerja penerimaan pajak dapat dideteksi dengan baik bagi pengelolaan kebijakan pajak di Indonesia.

Tujuan penelitian ini adalah memahami turbulensi lingkungan melalui fluktuasi ekonomi dari masing-masing variabel penyusun Tax Early Warning System (TEWS) yang telah disusun sebelumnya menggunakan metode siklus bisnis yang kemudian diindikasi akan mempengaruhi naik turunnya penerimaan pajak di beberapa Kanwil Pajak di Indonesia. Model ini diperlukan untuk merumuskan kebijakan strategis untuk mengantisipasi turbulensi lingkungan.
Salah satu pengaruh perubahan lingkungan terhadap perekonomian antara lain disebabkan terintegrasinya pasar finansial internasional. Penelitian yang dilakukan oleh Buch et.al (2005) menunjukkan bahwa terdapat hubungan signifikan antara pasar finansial dengan volatilitas siklus bisnis. Keterbukaan pasar finansial disuatu negara juga akan mempengaruhi fluktuasi perekonomian. Penelitian Fleming (1962), Mundell (1963) dan Dornbusch (1976) menyebutkan bahwa dalam kondisi nilai tukar fleksibel, dampak monetary policy shock terhadap output akan semakin besar tergantung dari kekuatan pergerakan modal (capital flow) di pasar internasional.

Studi fluktuasi ekonomi menurut pandangan Siregar (2002) dapat dikelompokkan menjadi dua bagian yaitu studi teoritik dan studi empirik. Studi teoritik lebih fokus pada identifikasi penyebab terjadinya siklus bisnis sehingga banyak disebut dengan traditional business cycle. Namun demikian dalam perkembangannya studi teoritik ini sudah banyak merevisi teori yang ada dengan menggunakan pendekatan yang lebih formal meskipun fokus utamanya masih pada pengujian pengaruh shock terhadap penawaran dan permintaan. Dalam perkembangannya studi teoritik ini kemudian dikenal dengan modern business cycle meliputi: (1) teori Real Business Cycle (RBC) dimana disebutkan bahwa shock lebih banyak disebabkan oleh faktor eksogen yaitu teknologi (King-Plosser, 1988), (2) teori New Keynes berpendapat bahwa siklus bisnis disebabkan oleh shock dari sisi permintaan (Cukierman, 2005) dan (3) teori Monetary Business Cycle (MBC) berpendapat bahwa uang memegang peranan penting terjadinya 
fluktuasi ekonomi terutama dalam pengendalian kebijakan moneter (Romer, 1996).

Sedangkan studi empirik siklus bisnis pada umumnya bertujuan untuk menguji pengaruh guncangan eksogen terhadap fluktuasi ekonomi, dengan melakukan dokumentasi fakta empirik (stylized facts) dan pendalaman melalui pengujian terhadap sejumlah teori. Studi terhadap siklus bisnis empirik sendiri dalam perkembangannya dibagi ke dalam dua pendekatan yaitu: (1) Econometric Business Cycle Research (EBCR) merupakan kombinasi teori ekonomi dan analisa fakta yang terjadi dalam siklus bisnis (Jacobs, 1998) dan (2) Non Econometric Business Cycle lebih bersifat "A theory" atau dikenal dengan teknik ekstraksi signal (Kaminsky, Lizondo dan Reinhart, 1997) karena melihat siklus bisnis sebagai sebuah fenomena fluktuasi ekonomi yang bersifat dynamic random walk.

Salah satu isu sentral dalam pembahasan sistem perekonomian internasional dengan keterbukaan sistem perdagangan adalah dampak guncangan terhadap stabilitas perekonomian nasional dalam kerangka small open economy. Pengaruh guncangan struktural dari variabel eksternal sebagai contoh nilai tukar akan menyebabkan perubahan harga domestik yang sering disebut dengan exchange rate pass trough effect (Hyder dan Syah, 2004). Dalam kerangka analisa siklus bisnis besarnya pengaruh dari setiap variabel tidak dapat diketahui secara jelas hanya arahnya saja, sehingga diperlukan analisis lain untuk mengetahui naik turunnya penerimaan pajak di beberapa Kanwil Pajak di Indonesia agar dapat diantisipasi melalui penerapan kebijakan strategis tertentu.

Untuk menganalisis pengaruh shock terhadap penerimaan pajak di beberapa
Kanwil Pajak tersebut akan digunakan model data panel (Hsiao, 2003; Frei-Campbell, 2006). Data panel memiliki dimensi waktu dan ruang. Data panel adalah jenis data yang mengkombinasikan data runut waktu (time series) dan kerat lintang (cross section), sehingga penggunaannya memiliki kelebihan tersendiri yaitu dapat menyediakan informasi yang cukup kaya untuk perkembangan teknik estimasi dan hasil teoretikal. Penggunaan data panel juga dimaksudkan untuk mengatasi keterbatasan jumlah data.

Jika setiap cross-section unit memiliki jumlah observasi time-series yang sama maka disebut sebagai balanced panel. Sebaliknya jika jumlah observasi berbeda untuk setiap cross-section unit maka disebut unbalanced panel. Beberapa keuntungan menggunakan data panel adalah karena:

1. Heterogeneity,

2. Lebih informatif, bervariasi, degree of freedom lebih besar dan lebih efisien,

3. Menghindari masalah multikolinearitas,

4. Lebih dapat mendeteksi dan mengukur pengaruh-pengaruh yang tidak dapat diobservasi pada data cross-section murni atau time-series murni,

Regresi data panel berbeda dari regresi time-series atau regresi cross-section biasa karena dalam regresi data panel setiap variabel mengandung subscript ganda it (Park, 2006). Rumusan umum untuk regresi data panel adalah sebagai berikut:

$\mathrm{Y}_{\mathrm{it}}=\alpha+\beta_{\mathrm{j}} \mathrm{X}_{\mathrm{it}}{ }^{\prime}+\mathrm{u}_{\mathrm{it}}$

dengan $\mathrm{i}=1, \ldots, \mathrm{N}$ menunjukkan rumah tangga, individu, perusahaan, negara dan sebagainya sedangkan $\mathrm{i}=1, \ldots, \mathrm{T}$ menunjukkan waktu. Oleh karena itu, i menandakan 
dimensi cross-section dan $\mathrm{t}$ menandakan dimensi waktu, $\alpha$ adalah intersep, $\beta$ adalah slope dan $\mathrm{X}_{\mathrm{it}}$ ' merupakan explanatory variable pada pengamatan it. Umumnya penerapan data panel menggunakan model one-way error component dalam bentuk:

$$
\mathrm{u}_{\mathrm{it}}=\mu_{\mathrm{i}}+\mathrm{v}_{\mathrm{it}}
$$

dimana $\mu_{i}$ menunjukkan pengaruh spesifik individu yang tidak dapat diamati dan $v_{i t}$ adalah sisaan disturbance. Nilai $\mathrm{u}_{\mathrm{it}}$ akan berbeda untuk setiap individual dan waktu sehingga merupakan disturbance yang biasa terjadi dalam analisis regresi. Dalam analisa model data panel dikenal tiga macam pendekatan yang terdiri dari pendekatan kuadrat terkecil (pooled least square), pendekatan efek tetap (fixed effect), dan pendekatan efek acak (random effect). Dalam penelitian ini model yang digunakan adalah pendekatan efek tetap (fixed effect).

Generalisasi secara umum yang sering dilakukan adalah dengan memasukkan variabel boneka (dummy variable) untuk menghasilkan nilai parameter yang berbeda-beda baik lintas unit cross section maupun antar waktu. Pendekatan dengan memasukkan variabel boneka ini dikenal dengan sebutan model efek tetap (fixed effect) atau Least Square Dummy Variable (LSDV). Penggunaan pendekatan efek tetap ini akan menghasilkan intersep yang berbeda-beda antar unit cross section. Pendekatan tersebut dapat dituliskan dalam persaman sebagai berikut:

$$
\mathrm{y}_{\mathrm{it}}=\alpha_{\mathrm{i}}+\mathrm{x}_{\mathrm{it}}^{\prime} \beta+\varepsilon_{\mathrm{it}}, \varepsilon_{\mathrm{it}} \sim \operatorname{IID}\left(0, \sigma_{\mathrm{e}}^{2}\right)
$$

dimana $x_{i t}$ independen terhadap $\varepsilon_{i t}$ dan $\alpha_{i}$ merupakan intersep yang berbeda-beda untuk masing-masing cross section. Kita dapat menuliskan model ini dalam kerangka regresi umumnya dengan memasukan variabel dummy untuk masing-masing unit $i$ dalam model. Dengan demikian,

$y_{i t}=\alpha+\sum_{j=2}^{N} \alpha_{j} \cdot d_{i j}+x_{i t}^{t} \beta+\varepsilon_{i t}$

dimana $\quad d_{i j}=1 \quad$ jika $i=j$ dan 0 untuk selainnya. Dengan begitu kita mempunyai variabel dummy sebanyak $N-1$ dalam model. Parameter $\alpha, \alpha_{1}, \ldots, \alpha_{N-1}$ dan $\beta$ dalam persamaan (4) dapat diestimasi dengan ordinary least square (OLS). Penak$\operatorname{sir} \beta$ disebut sebagai least square dummy variable (LSDV) estimator. Penyelesaian Secara numerik akan menjadi lebih rumit apabila kita memiliki model regresi dengan banyak regressor. Namun demikian, untuk mengestimasi $\beta$ dapat dihitung dengan cara yang lebih sederhana. Penaksir yang sama untuk $\beta$ dapat diperoleh jika regresi dilakukan dalam bentuk penyimpangan dari ratarata tiap individu. Pengaruh individu $\alpha_{1}$ dapat dihilangkan melalui proses transformasi data. Untuk itu perlu diperhatikan bahwa:

$$
\bar{y}_{i}=\alpha_{i}+\bar{x}_{i}^{\prime} \beta+\bar{\varepsilon}_{i},
$$

Dalam hal ini $\bar{y}_{i}=T^{-1} \sum_{t} y_{i t}$ dan begitu pula untuk variabel lainnya. Konsekuensinya kemudian dapat ditulis sebagai berikut: 
$y_{i t}-\bar{y}_{i}=\left(x_{i t}-\bar{x}_{i}\right)^{\prime} \beta+\left(\varepsilon_{i t}-\bar{\varepsilon}_{i}\right)$

Model ini adalah model regresi dalam bentuk penyimpangan rata-rata tiap individu dengan tidak memasukkan pengaruh individu $\alpha_{1}$. Transformasi yang menghasilkan observasi dalam bentuk penyimpangan dari ratarata tiap individu disebut sebagai within transformation. Penaksir OLS untuk $\beta$ yang diperoleh dari model transformasi ini disebut dengan fixed effect estimator, dimana model estimasi ini sangat identik dengan model LSDV. Dengan demikian persamaan LSDV dapat ditulis sebagai berikut ini.

$$
\begin{aligned}
\hat{\beta}_{\mathrm{FE}}= & \left(\sum_{\mathrm{i}=1}^{\mathrm{N}} \sum_{\mathrm{t}-1}^{\mathrm{T}}\left(\mathrm{x}_{\mathrm{it}}-\overline{\mathrm{x}}_{\mathrm{i}}\right)\left(\mathrm{x}_{\mathrm{it}}-\overline{\mathrm{x}}_{\mathrm{i}}\right)^{\prime}\right)^{-1} \\
& \sum_{\mathrm{i}=1}^{\mathrm{N}} \sum_{\mathrm{t}-1}^{\mathrm{T}}\left(\mathrm{x}_{\mathrm{it}}-\overline{\mathrm{x}}_{\mathrm{i}}\right)\left(\mathrm{y}_{\mathrm{it}}-\overline{\mathrm{y}}_{\mathrm{i}}\right) .
\end{aligned}
$$

Jika diasumsikan bahwa $X_{i t}$ adalah independen terhadap $\varepsilon_{i t}$, maka penaksir fixed effect adalah penaksir tidak bias untuk $\beta$. Jika asumsi normalitas untuk $\varepsilon_{i t}$ berlaku, maka $\hat{\beta}_{F E}$ akan terdistribusi normal. Agar tetap konsisten, maka diperlukan:

$$
\mathrm{E}\left\{\left(\mathrm{xit}-\overline{\mathrm{x}_{\mathrm{i}}}\right) \varepsilon_{\text {it }}\right\}=0
$$

Syarat cukup untuk kondisi ini adalah bahwa $x_{i t}$ tidak berkorelasi dengan $\varepsilon_{i t}$ dan $\bar{X}_{i}$ tidak berkorelasi dengan error term. Kondisi ini menunjukkan bahwa:

$$
\mathrm{E}\left\{\mathrm{x}_{\mathrm{it}} \varepsilon_{\text {is }}\right\}=0 \text { untuk semua } s, t
$$

dalam kasus ini kita menyebut $x_{i t}$ sebagai Strictly exogenous. Strictly exogenous variabel tidak boleh tergantung pada nilai saat ini, masa depan atau masa lalu dari error term. Karena variabel eksogen adalah independen terhadap semua error, maka intersep $N$ diestimasi dengan tidak bias sebagai berikut ini.

$$
\hat{\alpha}_{i}=\bar{y}_{i}-\bar{x}_{i}^{\prime} \hat{\beta}_{F E}, \quad i=1, \ldots, N
$$

Diasumsikan bahwa penaksir ini adalah konsisten untuk fixed effects $\alpha_{i}$ ketika $T$ menuju nilai tak hingga. Bagaimanapun, fixed effect model memusatkan perhatian pada perbedaan dalam individu, berarti, menjelaskan pula mengapa $y_{i t}$ berbeda dari $\bar{y}_{i}$ namun demikian tidak menjelaskan mengapa $\bar{y}_{i}$ berbeda dari $\bar{y}_{j}$. Pengaruh perubahan $X$ terhadap variabel lain yang ditangkap melalui parameter $\beta$ memiliki pengaruh yang sama, apakah itu perubahan dari satu periode ke periode yang lain atau perubahan dari satu individu ke individu yang lain.

Keputusan memasukkan variabel boneka ini harus didasarkan pada pertimbangan statistik. Tidak dapat kita pungkiri, dengan melakukan penambahan variabel boneka ini akan dapat mengurangi banyaknya degree of freedom yang pada akhirnya akan mempengaruhi efisiensi dari parameter yang diestimasi. Pertimbangan pemilihan pendekatan yang digunakan, didekati dengan menggunakan statistik F yang berusaha membanding- 
kan antara nilai jumlah kuadrat dari error proses pendugaan dengan menggunakan metode kuadrat terkecil dan efek tetap yang telah memasukkan variabel boneka. Rumusan untuk memperoleh nilai statistik tesebut adalah sebagai berikut:

$$
F_{N+T-2, N T-N-T}=\left(\frac{E S S_{1}-E S S_{2}}{N-1}\right)\left(\frac{N T-N-K}{E S S_{2}}\right)
$$

dimana $\mathrm{ESS}_{1}$ dan $\mathrm{ESS}_{2}$ adalah jumlah kuadrat sisa dengan menggunakan metode kuadrat terkecil biasa dan model efek tetap, sedangkan statistik $\mathrm{F}$ mengikuti distribusi $\mathrm{F}$ dengan derajat bebas N-1 dan NT-N-K . Nilai F-statistik uji ini kemudian dibandingkan dengan nilai statistik $F$ tabel yang akan menentukan pilihan model yang akan digunakan (Gujarati, 1995).

\section{METODE PENELITIAN}

Setelah pemetaan dampak shock terhadap penerimaan Pajak Penghasilan $(\mathrm{PPh})$ dan Pajak Pertambahan Nilai (PPN) dilakukan dengan terbentuknya TEWS melalui metode siklus bisnis, maka tahap selanjutnya adalah melakukan pengujian dampak shock ke tiaptiap kantor wilayah pelayanan. Hal ini dilakukan untuk mengetahui secara lebih mendalam mengenai prilaku siklus bisnis dan TEWS terhadap kinerja penerimaan pajak di beberapa kantor pelayanan di seluruh Indonesia untuk kemudian dapat disusun kebijakan strategis dan perumusan implikasiimplikasi kebijakan bagi Direktorat Jenderal Pajak dalam mengelola penerimaan negara dari sektor pajak sesuai fungsi budgeter-nya.

Outcome yang dihasilkan dari analisis ini merupakan feedback bagi Departemen
Keuangan itu sendiri, dimana indikator peringatan dini (leading indicator) dan cross section effect akan dipakai sebagai acuan kebijakan antisipatif baik yang berlaku secara internal maupun eksternal organisasi. Adapun prosedur yang harus dilakukan untuk melakukan analisis panel data adalah sebagai berikut:

1. Menyusun struktur data panel dengan rentang waktu tahun 2002 sampai dengan 2007 untuk 30 Kantor Wilayah di seluruh Indonesia,

2. Dalam penelitian ini akan dilihat pula hubungan kausalitas antara penerimaan pajak (PPh dan PPN) per Kantor Wilayah dengan indikator penyusun TEWS menggunakan metode Granger Causality,

3. Merata-ratakan seluruh indikator penyusun TEWS menjadi satu tahun dalam tahun yang bersangkutan,

4. Untuk memutuskan apakah akan menggunakan fixed effect atau random effect menggunakan uji Haussman. Hausman test dilakukan dengan hipotesa sebagai berikut:

\section{$\mathrm{H}_{0}$ : model random Effect \\ $\mathrm{H}_{1}$ : model fixed effect}

Sebagai dasar penolakan $\mathrm{H}_{0}$ maka digunakan statistik hausman dan membandingkannya dengan Chi square. Jika nilai $\chi^{2}$-statistik hasil pengujian lebih besar dari $\chi^{2}$ - tabel, maka cukup bukti untuk melakukan penolakan terhadap $\mathrm{H}_{0}$ sehingga pendekatan yang digunakan adalah fixed effect, begitu juga sebaliknya. 
5. Melakukan regresi panel dengan aplikasi Eviews 6.0 menggunakan format yang dilipih berdasarkan analisis poin (4).

\section{Pengumpulan Data}

Sumber data primer dan sekunder diperoleh berasal dari dari:

1. Data penerimaan pajak nasional diperoleh dari Dirjen Perbendaharaan,

2. Data makro ekonomi dalam negeri diperoleh dari website Bank Indonesia, Indikator Ekonomi Indonesia, SEKI (Statistik Ekonomi dan Keuangan Indonesia) dan CEIC,

3. Data perdagangan diperoleh dari Biro Pusat Statistik (BPS), Depertemen Perindustrian dan Departemen Perdagangan dan Bank Indonesia,

4. Data ekonomi internasional diperoleh dari website International Monetary Funds (IMF), Word Bank, National Beurau Economic Research (NBER), Beurau Labour Statistics (BLS), Federal Reserve (The Fed), Yahoo Finance, Google Finance dan CEIC.

Data penerimaan per Kanwil hanya diperoleh dalam bentuk data tahunan selama 6 tahun dengan rentang waktu tahun 2002 sampai dengan 2007. Sehingga dengan membentuk data panel untuk 30 lokasi Kanwil di seluruh Indonesia akan diperoleh hasil estimasi yang lebih baik dengan terjadinya peningkatan jumlah observasi yang berimplikasi terhadap peningkatan derajat kebebasan.

Dengan telah beberapa kali dilakukan proses pemecahan dan pengabungan wilayah kerja yang disebabkan oleh proses modernisasi dan efisiensi organisasi hal ini menyebabkan permasalahan tersendiri. Perubahan wilayah kerja terakhir dilakukan sehubungan dengan proses modernisasi organisasi yang dimulai tahun 2006, sehingga proses pengelompokkan wilayah kerja berdasarkan pada data pembentukan kantor operasional terakhir yaitu menurut Keputusan Menteri Keuangan Nomor: 55/PMK.01/2007.

Dari hasil pengelompokkan tersebut diperoleh data penerimaan pajak sebanyak 31 kelompok dengan rincian 29 Kantor Wilayah dan 2 Kantor Pelayanan Wajib Pajak Besar. Kedua KPP WP Besar ini sebenarnya masuk dalam kelompok Kanwil WP Besar, namun karena kedua KPP tersebut berperan sangat besar dalam mendukung porsi penerimaan pajak nasional maka analisisnya dipisahkan, sehingga hasil pengempokan tekahir diperoleh sebanyak 31 data panel kerat lintang. Total jumlah data observasi yang dapat diperoleh adalah 186 data. Daftar pengelompokan kantor wilayah pajak dapat dilihat dalam tabel 1.

\section{HASIL PENELITIAN DAN PEMBAHASAN}

\section{Hasil Analisis Data Panel}

Sebelum melakukan analisis data panel secara keseluruhan, terlebih dahulu dilakukan pengujian statistik untuk menentukan metode pendekatan apa yang akan dipakai. Dari ketiga pendekatan yang ada penggunaan pendekatan Pooled Least Square dirasakan kurang sesuai dengan tujuan digunakannya data panel. Oleh karena itu dalam penelitian ini hanya mempertimbangkan penggunaan pendekatan efek tetap dan efek acak saja. Untuk memutuskan apakah akan menggunakan fixed effect atau random effect maka digunakan uji Haussman. 
Tabel 1. Pengelompokan Kantor Wilayah di Indonesia

\begin{tabular}{llcc}
\hline No. & Kantor Wilayah DJP/KPP & Simbol & Jumlah KPP \\
\hline 1 & Jakarta Khusus & KW-01 & 10 \\
2 & KPP Wajib Pajak Besar 1 & WPB-1 & 1 \\
3 & KPP Wajib Pajak Besar 2 & WPB-2 & 1 \\
4 & KALSEL dan Kalteng & KW-03 & 4 \\
5 & Jakarta Selatan & KW-04 & 10 \\
6 & Jakarta Pusat & KW-05 & 16 \\
7 & Jawa Bagian Barat I & KW-06 & 6 \\
8 & Jakarta Utara & KW-07 & 5 \\
9 & Jakarta Barat & KW-08 & 7 \\
10 & Kalimantan Timur & KW-09 & 4 \\
11 & Riau dan Kepulauan Riau & KW-10 & 8 \\
12 & Jawa Bagian Barat II & KW-11 & 6 \\
13 & Jawa Bagian Timur I & KW-12 & 10 \\
14 & Jakarta Timur & KW-13 & 6 \\
15 & Sumsel dan Kep.Babel & KW-14 & 7 \\
16 & Jawa Bagian Tengah II & KW-15 & 8 \\
17 & Jawa Bagian Timur III & KW-16 & 8 \\
18 & Sumatera Bagian Utara I & KW-17 & 7 \\
19 & Jambi & KW-18 & 2 \\
20 & Jawa Bagian Timur II & KW-19 & 7 \\
21 & Jawa Bagian Tengah I & KW-20 & 9 \\
22 & Sulut, Sulteng, Gorontalo, Malut & KW-21 & 4 \\
23 & Kalimantan Barat & KW-22 & 2 \\
24 & Bengkulu dan Lampung & KW-23 & 3 \\
25 & Nanggroe Aceh Darussalam & KW-24 & 3 \\
26 & Sumatera Bagian Utara li & KW-25 & 5 \\
27 & Bali & KW-26 & 4 \\
28 & Papua dan Maluku & KW-27 & 5 \\
29 & Banten & KW-28 & 9 \\
30 & NTB dan NTT & KW-29 & 5 \\
31 & Sulsel dan Sultra & KW-30 & 5 \\
\hline & & & \\
\hline
\end{tabular}

Keterangan:

pengelompokan berdasarkan Keputusan Menteri Keuangan Nomor: 55/PMK.01/2007

Dengan menggunakan aplikasi Eviews 6.0 diperoleh hasil nilai statistik Hausman test sebesar 45.321 untuk dependen variabel $\mathrm{PPh}$ dan 37.245 untuk dependen variabel PPN serta nilai probabilitas ditemuan pula sebesar 0.000 . Nilai ini berarti lebih kecil dari nilai Chi-Square tabel (dimana $\chi_{\text {tabel }}^{2}=$ 23.685) dengan demikian berarti hipotesis untuk menggunakan efek acak ditolak, sehingga disimpulkan pendekatan efek tetap lebih baik digunakan pada penelitian ini.

Dengan demikian dari hasil analisis sebagaimana yang ditunjukkan dalam tabel 2 dan tabel 3 di atas, variabel ekonomi yang tidak berpengaruh signifikan terhadap $\mathrm{PPh}$ pada taraf kurang dari 5 persen untuk uji 1 sisi adalah variabel MVP dan IDR/USD. Kemudian uji koefisien determinasi $\left(\mathrm{R}^{2}\right)$ 


\section{Tabel 2. Hasil Analisis Data Panel Berdasarkan Pendekatan Efek Tetap dengan Dependen Variabel PPH}

\begin{tabular}{lrrrrrr}
\hline \multirow{2}{*}{ Variable (X) } & \multirow{2}{*}{ Coeff } & t-Statistic & Prob. & \multicolumn{2}{c}{ GC F-test } \\
\cline { 5 - 7 } & & & & X $\rightarrow$ PPh & PPh $\rightarrow \mathbf{X}$ \\
\hline Producer Price Index (PPI) & 1.278 & $12.642^{*}$ & 0.000 & 2.306 & 0.415 \\
Wholesale Price Index (WPI) & 1.303 & $12.755^{*}$ & 0.000 & 2.390 & 0.477 \\
Konsumsi minyak (OILCon) & 3.805 & $5.773^{*}$ & 0.000 & 2.152 & 0.478 \\
Hotel Ocunpancy rate (HOR) & 3.170 & $10.461^{*}$ & 0.000 & 2.067 & 0.349 \\
Jumlah penjualan mobil (MVP) & 0.078 & 0.833 & 0.406 & 2.233 & 0.500 \\
Physical currency + demand deposit (M1) & 0.916 & $13.094^{*}$ & 0.000 & 2.377 & 0.157 \\
M1 + time deposit (M2) & 1.276 & $12.959^{*}$ & 0.000 & 2.543 & 0.261 \\
Kurs Rupiah thd. USD (IDR_USD) & 1.112 & 1.612 & 0.109 & 1.159 & 0.606 \\
Kurs USD thd. Yen (USD_JPY) & -1.113 & $-1.912^{* *}$ & 0.057 & 1.478 & 0.321 \\
Harga minyak (OILPr) & 0.590 & $12.414^{*}$ & 0.000 & 2.375 & 0.424 \\
Inflasi US (USINFL) & 0.791 & $9.098^{*}$ & 0.000 & 2.183 & 0.323 \\
\hline
\end{tabular}

Note: * significant at the $5 \%$ level, ${ }^{* *}$ significant at the $10 \%$ level

Tabel 3. Hasil Analisis Data Panel Berdasarkan Pendekatan Efek Tetap dengan Dependen Variabel PPN

\begin{tabular}{lrrrrr}
\hline \multirow{2}{*}{ Variable (X) } & \multirow{2}{*}{ Coeff } & t-Statistic & Prob. & \multicolumn{2}{c}{ GC F-test } \\
\cline { 5 - 6 } & & & & X $\rightarrow$ PPN & PPN $\rightarrow \mathbf{X}$ \\
\hline GDP Transport \& Communications (GDP_TC) & 0.450 & $5.226^{*}$ & 0.000 & 7.891 & 2.029 \\
GDP from Services sector (GDP_Serv) & 0.549 & $5.366^{\star}$ & 0.000 & 7.631 & 5.410 \\
Cadangan devisa (CD) & 1.082 & $6.301^{*}$ & 0.000 & 3.800 & 0.933 \\
Impor (IMP) & 0.440 & $4.538^{*}$ & 0.000 & 8.516 & 1.049 \\
Ekspor (EXP) & 0.610 & $5.009^{*}$ & 0.000 & 7.509 & 0.299 \\
Harga gas (GASPr) & 0.370 & $4.743^{*}$ & 0.000 & 7.178 & 0.405 \\
Suku bunga Sibor 3 bulan (SIBOR3m) & 0.192 & $3.481^{*}$ & 0.001 & 8.169 & 0.194 \\
\hline
\end{tabular}

Note: * significant at the $5 \%$ level, ${ }^{\text {* }}$ significant at the $10 \%$ level

dilakukan untuk menguji seberapa besar persentase variasi variabel bebas dapat menjelaskan variasi variabel tak bebasnya, atau menggambarkan tentang goodness of fit dari persamaan regresi. Berdasarkan Rule of thumb semakin tinggi $\mathrm{R}^{2}$ maka persamaan regresi dianggap semakin baik apabila asumsi-asumsi klasik telah terpenuhi. Dari hasil analisis di atas nilai $\mathrm{R}^{2}$ yang dihasilkan tidak besar yaitu untuk PPh adalah 0,293 dan PPn adalah 0,119.

\section{Analisis Efek Cross Section Antarwilayah}

Dari hasil analisis data panel tersebut dapat dilihat pula fungsi fixed cross section effect 
sehinga diketahui pengaruh fluktuasi TEWS terhadap penerimaan pajak per wilayah. Memang dari analisis ini tidak dapat secara jelas dilihat pengaruh variabel independen terhadap dependennya di setiap kantor wilayah. Namun demikian dari cross section effect tersebut minimal dapat dilihat efek positif dan negatif variabel independen dalam hal ini indikator TEWS terhadap penerimaan $\mathrm{PPh}$ dan PPN. Hasil analisis Fixed cross section effect dapat dilihat dalam tabel 4.
Dari hasil analisis tersebut dapat dilihat bahwa Kanwil DJP yang paling besar merasakan efek dari perubahan indikator TEWS adalah kanwil Jakarta Khusus (KW01) baik penerimaan sektor $\mathrm{PPh}$ (1.329) dan sektor PPN (1.346), kemudian diikuti oleh KPP WP Besar 1 dan 2 (Kanwil WP Besar). Hal ini sangat masuk akal karena jika dilihat kontribusi penerimaan pajak dari kedua Kanwil tersebut sangat signifikan terhadap APBN.

Hampir seluruh penerimaan $\mathrm{PPh}$ Kanwil di Jakarta, Jawa Tengah dan Jawa Barat

Tabel 4. Fixed Cross Section Effect Variabel Tews terhadap Reference Series

\begin{tabular}{|c|c|c|c|}
\hline \multirow{2}{*}{ Kantor Wilayah DJP/KPP } & \multirow{2}{*}{ Simbol } & \multicolumn{2}{|c|}{$\begin{array}{c}\text { Fixed cross section } \\
\text { effect }\end{array}$} \\
\hline & & PPh & PPN \\
\hline Jakarta Khusus & KW-01 & $1.329 *$ & $1.346^{*}$ \\
\hline KPP Wajib Pajak Besar 1 & WPB-1 & $0.938 *$ & 0.423 \\
\hline KPP Wajib Pajak Besar 2 & WPB-2 & $0.663^{*}$ & $0.892^{*}$ \\
\hline Kalsel dan Kalteng & KW-03 & -0.351 & -0.378 \\
\hline Jakarta Selatan & KW-04 & 0.471 & 0.445 \\
\hline Jakarta Pusat & KW-05 & 0.482 & 0.521 \\
\hline Jawa Bagian Barat I & KW-06 & 0.251 & 0.240 \\
\hline Jakarta Utara & KW-07 & -0.093 & 0.239 \\
\hline Jakarta Barat & KW-08 & -0.052 & 0.259 \\
\hline Kalimantan Timur & KW-09 & 0.144 & -0.003 \\
\hline Riau dan Kepulauan Riau & KW-10 & 0.290 & 0.120 \\
\hline Jawa Bagian Barat II & KW-11 & 0.209 & 0.288 \\
\hline Jawa Bagian Timur I & KW-12 & 0.253 & 0.313 \\
\hline Jakarta Timur & KW-13 & 0.115 & 0.195 \\
\hline Sumsel dan Kep.Babel & KW-14 & -0.138 & -0.146 \\
\hline Jawa Bagian Tengah II & KW-15 & -0.139 & -0.212 \\
\hline Jawa Bagian Timur III & KW-16 & -0.079 & 0.182 \\
\hline Sumatera Bagian Utara I & KW-17 & 0.011 & $-0.704^{*}$ \\
\hline Jambi & $\mathrm{KW}-18$ & $-0.724^{*}$ & $-0.531^{*}$ \\
\hline Jawa Bagian Timur II & KW-19 & -0.100 & 0.083 \\
\hline Jawa Bagian Tengah I & KW-20 & 0.008 & 0.156 \\
\hline Sulut, Sulteng, Gorontalo, Malut & $\mathrm{KW}-21$ & -0.383 & -0.363 \\
\hline Kalimantan Barat & $\mathrm{KW}-22$ & $-0.666^{\star}$ & $-0.600^{*}$ \\
\hline Bengkulu dan Lampung & $\mathrm{KW}-23$ & -0.403 & -0.238 \\
\hline Nanggroe Aceh Darussalam & $\mathrm{KW}-24$ & $-0.530^{\star}$ & $-0.502^{*}$ \\
\hline Sumatera Bagian Utara II & KW-25 & $-0.506^{*}$ & $-0.508^{*}$ \\
\hline Bali & KW-26 & -0.339 & $-0.604^{*}$ \\
\hline Papua dan Maluku & KW-27 & -0.233 & -0.249 \\
\hline Banten & $\mathrm{KW}-28$ & 0.285 & 0.153 \\
\hline NTB dan NTT & KW-29 & -0.489 & $-0.625^{*}$ \\
\hline Sulsel dan Sultra & KW-30 & -0.226 & -0.192 \\
\hline
\end{tabular}

Keterangan: tanda $\left({ }^{*}\right)$ menunjukkan efek cross section bernilai $>0.5$ 

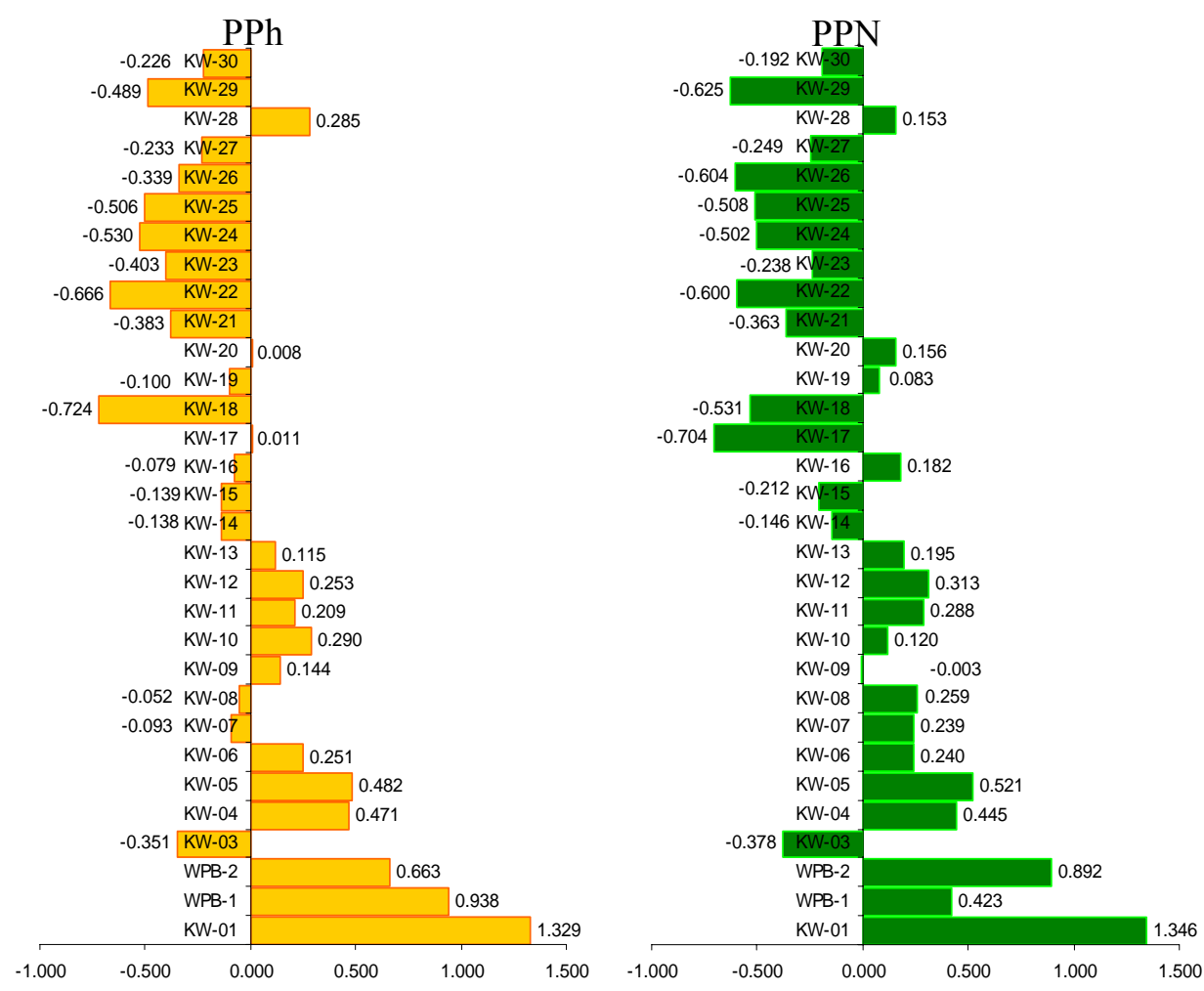

Gambar 1. Grafik Fixed Cross Section effect Indikator TEWS terhadap PPh dan PPN

memiliki efek positif terhadap perubahan variabel TEWS. Sedangkan Kanwil di luar Jawa yang juga memiliki efek positif adalah Kanwil Riau dan Kepulauan Riau (KW-10) sebesar 0,29 serta Kanwil Kalimantan Selatan dan Tengah sebesar 0,892. (lihat gambar 1)

Dari hasil analisis fixed cross section effect variabel TEWS terhadap series acuan dapat dilihat bahwa perubahan variabel TEWS terhadap $\mathrm{PPh}$ memberikan efek positif terbesar terhadap Kanwil Khusus (KW-01), Kanwil WP Besar 1 (WPB-1), Kanwil WP Besar 2 (WPB-2), Kanwil Jakarta Selatan, Kanwil Jakarta Pusat,
Kanwil Jawa Bagian Barat I, Kanwil Riau dan Kepulauan Riau (KW-10) serta Kanwil Kalimantan Selatan dan Tengah. Peta respon per wilayah untuk $\mathrm{PPh}$ dapat dilihat dalam gambar 2.

Pada gambar di atas khusus wilayah DKI Jakarta Kanwil Jakarta Barat (KW-08) dan Kanwil Jakarta Utara (KW-07) memeiliki efek negatif terhadap TEWS PPh, namun demikian jika dilihat kontribusi penerimaannya terhadap total penerimaan PPh Kanwil Jakarta kontribusinya hanya sebesar 1.61 persen dan 1.79 persen saja. Sedangkan dari gambar 3 terlihat bahwa respon penerimaan 


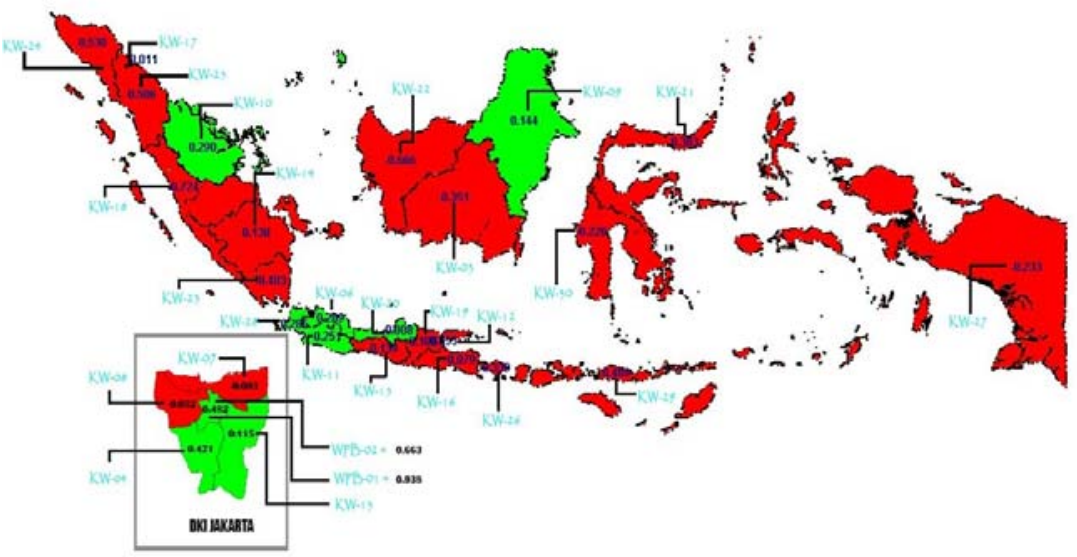

Gambar 2. Peta respon wilayah terhadap fluktuasi TEWS dengan reference series PPh (Warna hijau menunjukkan wilayah dengan respon positif dan merah negatif)

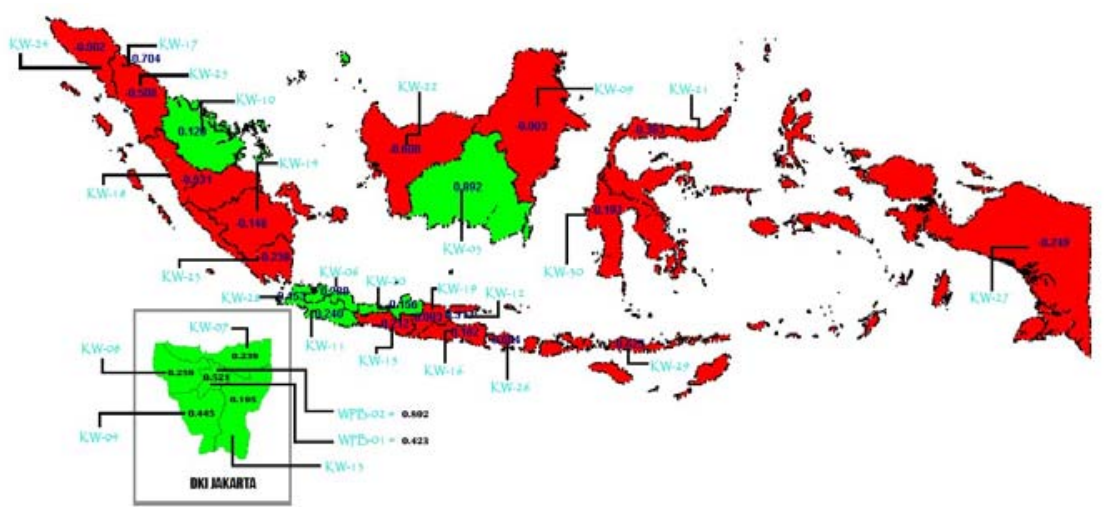

\section{Gambar 3. Peta Respon Wilayah terhadap Fluktuasi TEWS dengan Reference Series PPN} (warna hijau menunjukkan wilayah dengan respon positif dan merah negatif)

PPN di seluruh Kantor Wilayah DKI Jakarta memiliki efek positif.

Dari peta tersebut dapat dilihat bahwa ternyata fluktuasi indikator penyusun TEWS lebih berdampak negatif terhadap penerimaan pajak baik sektor PPh maupun PPN di wilayah-wilayah luar pulau Jawa. Hal ini dapat dijelaskan bahwa sebagian besar wilayah di luar Pulau Jawa merupakan daerah penghasil dengan sumber utama berasal dari natural resources dimana daerah pemasarannya adalah pulau Jawa. Transportasi merupakan permasalahan utama dalam proses distribusi barang, dimana komponen biaya sangat dipengaruhi oleh BBM. Padahal berdasarkan hasil analisis terdahulu diketahui secara jelas bahwa harga minyak merupakan faktor penting yang mempengaruhi fluktuasi siklus bisnis Indonesia. Dengan demikian dampaknya akan menurunkan produktifitas daerah penghasil (cost push). 


\section{Strategi Pengamanan Penerimaan Pajak}

Dari sudut pandang ekonomi, pajak adalah salah satu primadona penerimaan negara yang paling potensial. Bahkan, saat ini sektor pajak memberikan kontribusi yang terbesar dalam APBN. Hal ini menunjukkan bahwa betapa pentingnya pajak bagi negara karena pajak merupakan sumber dana yang diperuntukkan bagi pembiayaan pengeluaran negara/ pemerintah. Untuk melakukan sinkronisasi kebijakan sehubungan dengan pengaruh turbulensi lingkungan yang mempengaruhi keseimbangan APBN melalui mekanisme manajemen pengendalian penerimaan pajak secara efektif berdasarkan identifikasi TEWS indikator maka perlu dilakukan manajemen penyelarasan.

Strategi yang dimaksud di sini adalah suatu kumpulan perilaku dan seperangkat tindakan yang dibutuhkan untuk mencapai sasaran dengan cara-cara yang sistematis, efektif, dan efisien sesuai dengan sinyalsinyal fluktuasi yang telah diidentifikasi melalui TEWS. Sasaran atau target yang akan dicapat itu sendiri memberikan pengertian tentang sesuatu yang dituju atau sesuatu yang hendak dicapai. Pencapaian sasaran perpajakan harus memperhatikan kedua belah sisi baik dari sisi fiskus sebagai pelaksana pemungutan pajak dan sisi Wajib Pajak selaku pembayar pajak.

Paling tidak terdapat lima variabel penting untuk dikendalikan yaitu konsumsi minyak, harga minyak, inflasi dalam negeri, uang beredar dan nilai tukar. Strategi pengendalian dalam rangka pengamanan penerimaan pajak didasarkan pada sinyal yang diberikan oleh TEWS. Dalam tatanan agregat nasional dalam hal ini Departemen Keuangan Republik Indonesia bertindak sebagai pengendali fiskal tidak dapat berdiri sendiri diperlukan koordinasi yang harmonis dengan pihak lain yaitu Bank Indonesia sebagai pengendali sistem moneter. Hal ini perlu dilakukan karena berdasarkan hasil analisis terlihat bahwa salah satu penyebab fluktuasi ekonomi adalah nilai tukar, dimana penjaga stabilitas nilai tukar berada dalam jangkauan bidang tugas Bank Indonesia. Sedangkan hampir semua variabel penyusun TEWS berada di luar kendali Direktorat Jenderal Pajak (DJP). Sehingga dalam hal ini posisi DJP bukan merupakan kendali kebijakan dalam level agregat makro.

Pengendalian kelima variabel tersebut berada di dua institusi yang berbeda. Pengendali konsumsi minyak, harga minyak dan inflasi merupakan domain dari Departemen Keuangan sedangkan pengendalian jumlah uang beredar dan nilai tukar merupakan bidang tugas Bank Indonesia. Dengan demikian strategi yang akan diterapkan oleh DJP juga bukan merupakan strategi pengelolaan makro ekonomi melainkan lebih bersifat strategi antisipatif dalam hal manajemen pengamanan penerimaan negara.

DJP adalah salah satu bagian organisasi yang bertanggung jawab terhadap pelaksanaan manajemen pengamanan penerimaan negara di Departemen Keuangan Republik Indonesia memiliki peran sentral dalam mengelola penerimaan pajak melalui proses manajemen seperti telah dijelaskan di atas. DJP bertugas merencanakan sistem pengamanan penerimaan negara untuk mencapai sasaran strategik organisasi secara keseluruhan. Departemen Keuangan secara periodik memantau dan mengevaluasi hasil pelaksanaan rencana pengamanan penerimaan yang dilakukan oleh DJP sebagai bahan kajian dalam membuat evaluasi pencapaian sasaran strategik organisasi. Dari hal tersebut 
terlihat bahwa manajemen antisipatif yang dilakukan DJP memiliki peranan yang penting dalam pencapaian sasaran organisasi induk dalam hal ini Departemen Keuangan. Oleh karena itu DJP harus memilki kemampuan untuk memantau dan mengendalikan pelaksanaan rencana dalam rangka pengamanan penerimaan pajak.

Menurut Hermawan Kartajaya (1998), pada suatu organisasi baik pemerintah maupun swasta, akan terjadi suatu proses manajemen yang melibatkan value (V), strategy (S) dan tactic (T) dalam suatu siklus tertutup dan timbal balik. Ketiganya mempunyai peran berbeda dalam sebuah organisasi dan saling mempengaruhi. Jika dianalogkan dengan perusahaan maka strategi berisi tentang bagaimana cara organisasi dapat merebut mind share, dalam hal ini DJP perlu menentukan posisi wajib pajak yang akan dijadikan sebagai target utama, menengah dan bawah. Sedangkan tactic tentang bagaimana organisasi merebut market share dalam hal ini organisasi DJP perlu menangkap seluruh sektor ekonomi yang memberikan manfaat perpajakan tinggi untuk meningkatkan penerimaan negara dan value adalah tentang bagaimana organisasi merebut heart share dalam hal ini DJP perlu membentuk citra positif di masyarakat melalui pelayanan prima sehingga kesadaran dalam membayar pajak menjadi suatu kebutuhan bukan merupakan sebuah beban. Ketiga unsur tersebut merupakan suatu hal yang sangat penting bagi organisasi manapun karena secara bersama-sama unsur-unsur ini akan membentuk grand design dari sebuah organisasi.

Seluruh usaha tersebut tidak lain adalah untuk menciptakan harmonisasi hubungan antara fiskus dan wajib pajak sehingga visi serta misi DJP dapat terwujud dengan baik melalui pencapaian indikator kesuksesan berupa peningkatan tax ratio, peningkatan jumlah WP OP, penurunan jumlah WP non filer dan meningkatnya image positif DJP dapat terjadi secara optimal.

\section{KESIMPULAN}

Tujuan yang dihasilkan dalam penelitian ini adalah memahami turbulensi lingkungan melalui fluktuasi ekonomi dari masingmasing variabel penyusun Tax Early Warning System (TEWS) yang telah disusun sebelumnya menggunakan metode siklus bisnis yang kemudian akan mempengaruhi naik turunnya penerimaan pajak di beberapa Kanwil Pajak di Indonesia. Dari hasil analisis data panel terhadap 31 Kanwil DJP seluruh Indonesia diketahui bahwa fluktuasi variabel TEWS berpengaruh positif terhadap kinerja penerimaan pajak di Kanwil Khusus, Kanwil WP Besar 1 dan 2, Kanwil Jakarta Selatan dan Kanwil Jakarta Pusat.

Paling tidak terdapat lima variabel penting untuk dikendalikan yaitu konsumsi minyak, harga minyak, inflasi dalam negeri, uang beredar dan nilai tukar. Strategi pengendalian dalam rangka pengamanan penerimaan pajak didasarkan pada sinyal yang diberikan oleh TEWS. Dalam tatanan agregat nasional dalam hal ini Departemen Keuangan Republik Indonesia bertindak sebagai pengendali fiskal tidak dapat berdiri sendiri diperlukan koordinasi yang harmonis dengan pihak lain yaitu Bank Indonesia sebagai pengendali sistem moneter. Sedangkan hampir semua variabel penyusun TEWS berada di luar kendali Direktorat Jenderal Pajak (DJP). Sehingga dalam hal ini posisi DJP bukan merupakan kendali kebijakan dalam level agregat makro. Dengan demikian 
strategi yang akan diterapkan oleh DJP juga bukan merupakan strategi pengelolaan makro ekonomi melainkan lebih bersifat strategi antisipatif dalam hal manajemen pengamanan penerimaan negara.

Di samping itu penyelarasan antara kebijakan yang diterapkan untuk stabilisasi penerimaan harus pula dapat menciptakan pengaruh yang kondusif terhadap dunia usaha, sehingga perlu diterapkan strategi tertentu dalam sistem perpajakan. Strategi yang dimaksud di sini adalah suatu kumpulan perilaku dan seperangkat tindakan yang dibutuhkan untuk mencapai sasaran dengan cara-cara yang sistematis, efektif, dan efisien sesuai dengan sinyal-sinyal fluktuasi yang telah diidentifikasi melalui TEWS dan pola kerangka kerja manajemen antisipatif berupa Strategy, Value dan Tactic.

Seluruh usaha tersebut tidak lain adalah untuk menciptakan harmonisasi hubungan antara fiskus dan wajib pajak sehingga visi serta misi DJP dapat terwujud dengan baik melalui pencapaian indikator kesuksesan berupa peningkatan tax ratio, peningkatan jumlah WP OP, penurunan jumlah WP non filer dan meningkatnya image positif DJP dapat terjadi secara optimal.

\section{DAFTAR PUSTAKA}

Baltagi Badi H. 2006. Forecasting with panel data, Discussion Paper Series 1: Economic Studies No 25/2006, Deutsche Bundesbank, Wilhelm-Epstein-Strasse 14, 60431 Frankfurt am Main,

Butch Claudia M, Doepke Joerg, Pierdzioch Christian. 2005. Financial Openness and Business Cycle Volatility, Journal of Financial Money and Finance, Vol. 24, pp. 733-765,
Cukierman Alex. 2005. Keynesian Economics, Monetary Policy and the Business Cycle-New and Old, CESifo Economic Studies, Vol. 51, 4/2005, 697-728,

Dornbusch, R. 1976. Expectations and Exchange Rate Dynamics, Journal of Political Economy 84, pp.1161-1176,

Flemming, JM. 1962. Domestic Financial Policies under Fixed and Under Floating Exchange Rates, American Economic Review, Vol. 90, pp. 369379 ,

Frei Frances X., Campbell Dennis. 2006. Introduction to Panel Data, USA: Harvard Business School.

Gujarati Damodar N. 1995. Basic Econometric, International Edition, New York: McGraw Hill

Hsiao Cheng. 2003. Analysis of Panel Data, London: Cambridge University Press,

Hyder Zulfiqar, Shah Sardar, 2004, Exchange Rate Pass-Through to Domestic Prices in Pakistan, Working Papers, State Bank of Pakistan,

Jacobs Jan. 1998. Econometric Business Cycle Research: an Assessment of Method, $\mathrm{Ph}$.D. dissertation at the University of Groningen, presented at the CCSO seminar, Groningen,

Kaminsky, Graciela, Saul Lizondo, Carmen Reinhart. 1997. Leading Indicators of Currency Crises, Policy Research Working Paper, No. 1852, Washington, D.C.: The World Bank,

Kartajaya, H, 1998, Marketing Plus 2000: Siasat Memenangkan Persaingan Global, Jakarta: Gramedia Pustaka Media.

King Robert G., Plosser Charles, Rebelo Sergio. 1988. Production, Growth and 
Business Cycle I. The Basic Neoclassical Model, Journal of Monetary Economics, Vol. 21, pp. 195-232,

Mundell, RA. 1963. Capital Mobility and Stabilization Policy Under Fixed and Flexible Exchange Rate, Canadian Journal of Economics and Political Science, Vol. 29, pp. 475-485,

Park Hun Myoung. 2008. Linear Regression Models for Panel Data Using SAS, STATA, LIMDEP, and SPSS, the Trustees of Indiana University, http:/ /www.indiana. edu/ statmath,
Romer, D. 1996. Advanced Macroeconomics, New York: The McGraw-Hill Companies, Inc.

Siregar Hermanto. 2002. Empirical Evaluation of Rival Theories of the Business Cycle: Applications of Structural VAR Models to New Zealand Economy, PhD. Thesis, Lincoln University, Canterbury, 